\title{
Incidence of end-stage renal disease in Type 2 (non-insulin-dependent) diabetes mellitus in Pima Indians
}

\author{
R. G. Nelson ${ }^{1}$, J. M. Newman ${ }^{2}$, W.C. Knowler ${ }^{1}$, M. L. Sievers ${ }^{1}$, C. L. Kunzelman ${ }^{1}$, D. J. Pettitt ${ }^{1}$, C. D. Moffett ${ }^{3}$, \\ S.M. Teutsch ${ }^{2}$ and P.H. Bennett ${ }^{1}$ \\ ${ }^{1}$ Diabetes and Arthritis Epidemiology Section, National Institute of Diabetes and Digestive and Kidney Diseases, Phoenix, Arizona, \\ ${ }^{2}$ Division of Diabetes Control, Centers for Disease Control, Atlanta, Georgia, and \\ ${ }^{3}$ Gila River Indian Community Human Resources Department, Sacaton, Arizona, USA
}

\begin{abstract}
Summary. The incidence of end-stage renal disease was determined in the Pima Indians of the Gila River Indian Community in Arizona, a population with a high prevalence of Type 2 (non-insulin-dependent) diabetes mellitus. Between 1975 and 1986, from a study population of 5059 subjects, end-stage renal disease occurred in 80 persons, 76 $(95 \%)$ of whom had Type 2 diabetes. A review of the cases with end-stage renal disease indicated that among the diabetic subjects only two cases could be attributed to nondiabetic renal disease; all other cases were attributable to diabetic nephropathy. In diabetic Pima Indians the incidence rate of end-stage renal disease did not change during the study period, was similar in men and women, and was not effected by age at diagnosis of diabetes or by attained age, but did in-
\end{abstract}

crease significantly with hypertension $(p<0.05)$. The incidence of end-stage renal disease attributed to diabetic nephropathy increased from 0 cases $/ 1000$ person-years at $0-5$ years to 40.8 cases $/ 1000$ person-years at $\geq 20$ years duration of diabetes. In these subjects with Type 2 diabetes, the incidence rate of end-stage renal disease was similar to that in subjects with Type 1 (insulin-dependent) diabetes who were followed at the Joslin Clinic in Boston, Massachusetts when those with similar duration of diabetes were compared.

Key words: End-stage renal disease, diabetic nephropathy, Type 2 (non-insulin-dependent) diabetes, incidence, Pima Indians.
Diabetes is the leading cause of dialysis-treated endstage renal disease (ESRD) in persons aged 25-64 years in the United States, accounting for nearly $25 \%$ of new cases [1]. Although ESRD is a well recognised complication of long-duration Type 1 (insulin-dependent) diabetes, about half of the ESRD associated with diabetes occurs in subjects with Type 2 (non-insulindependent) diabetes [2]. Only very limited data are available, however, on the incidence rate of ESRD among persons with Type 2 diabetes.

In the present study, the incidence rate of ESRD was determined in the Pima Indians of the Gila River Indian Community in Arizona, a population with the world's highest reported prevalence of Type 2 diabetes [3]. The effects of hypertension, age at diagnosis of diabetes, attained age, and duration of diabetes on the incidence of ESRD were evaluated; and the incidence of ESRD in Pima Indians was compared with previously published rates. In the Pima Indians, diabetic nephropathy is qualitatively indistinguishable, both clinically and pathologically, from the manifestations described in other populations [4]. Furthermore, among Pima Indians, clinical and anatomic evidence of chronic renal disease occurs in high frequency and predominantly in persons with diabetes $[4,5]$.

\section{Subjects and methods}

The National Institutes of Health has conducted a longitudinal study of diabetes and its complications in the Gila River Indian Community of Arizona since 1965 [6]. This community is inhabited primarily by Pima and Papago Indians. Approximately every two years each resident of the cornmunity who is at least 5 years of age is asked to participate in a standardised medical examination, regardless of health.

These biennial examinations include a modified glucose tolerance test with determination of the glucose concentration in venous plasma drawn $2 \mathrm{~h}$ after the ingestion of a $75-\mathrm{g}$ carbohydrate load (Glucola, Ames Company, Elkhart, Ind, USA; Dexcola, Custom Laboratories, Baltimore, Md, USA; or Koladex, Custom Laboratories, Baltimore, Md, USA). Diabetes is diagnosed according to World Health Organisation criteria [7] if the $2 \mathrm{~h}$ post-load plasma glucose concentration is at least $11.1 \mathrm{mmol} / \mathrm{l}$. The date of diagnosis of diabetes is determined from these biennial examinations or from review of clinical records if diabetes is diagnosed in the course of routine medical care other than at biennial examinations. Systolic and diastolic blood pressures are measured at the first and fourth Korotkoff sounds, respectively, with the subject resting in the supine position. For the present study hypertension was arbitrarily defined by a systolic blood pressure $\geq 160 \mathrm{~mm} \mathrm{Hg}$ or a diastolic blood pressure $\geq 95 \mathrm{~mm} \mathrm{Hg}$.

The study population of 5059 subjects at risk for ESRD consisted of all persons five years of age or older who lived in the Gila River Indian Community at any time between January 1, 1975 and June 30,1986 , whose heritage was at least 50\% Pima, Papago, or a mixture 
Table 1. Numbers of subjects in the Pima Indian population at the beginning of the followup period according to attained age, diabetes status, and diabetes duration

\begin{tabular}{|c|c|c|c|c|c|c|c|c|}
\hline \multirow{2}{*}{$\begin{array}{l}\text { Attained } \\
\text { age (years) }\end{array}$} & \multirow[b]{2}{*}{ Nondiabetic } & \multicolumn{5}{|c|}{ Diabetes duration (years) } & \multirow[b]{2}{*}{ Total } & \multirow[b]{2}{*}{$(\%)$} \\
\hline & & $0-4$ & $5-9$ & $10-14$ & $15-19$ & $\geq 20$ & & \\
\hline $5-34$ & 3673 & 96 & 40 & 4 & 2 & 1 & 3816 & $(75.4)$ \\
\hline $35-44$ & 285 & 83 & 68 & 25 & 9 & 2 & 472 & $(9.3)$ \\
\hline $45-54$ & 163 & 56 & 71 & 35 & 12 & 8 & 345 & (6.8) \\
\hline $55-64$ & 87 & 18 & 31 & 40 & 16 & 9 & 201 & $(4.0)$ \\
\hline $65-74$ & 48 & 12 & 23 & 32 & 15 & 15 & 145 & (2.9) \\
\hline$\geq 75$ & 53 & 4 & 13 & 6 & 4 & 0 & 80 & (1.6) \\
\hline Total & 4309 & 269 & 246 & 142 & 58 & 35 & 5059 & $(100)$ \\
\hline$(\%)$ & $(85.2)$ & $(5.3)$ & (4.9) & $(2.8)$ & (1.1) & $(0.7)$ & $(100)$ & \\
\hline
\end{tabular}

Note: Of the 4309 nondiabetic subjects at entry, 387 were subsequently diagnosed as having diabetes during the followup period

Table 2. Person-years at risk, number of cases, and incidence of end-stage renal disease in diabetic and nondiabetic Pima Indians ${ }^{\mathrm{a}}$

\begin{tabular}{lccl}
\hline Diabetes & $\begin{array}{l}\text { Person-years } \\
\text { at risk }\end{array}$ & Cases & Incidence $^{\text {b }}$ \\
\hline No & 29,686 & 4 & 0.1 \\
Yes & 8,106 & 76 & 9.4 \\
Total & 37,792 & 80 & 2.1 \\
\hline
\end{tabular}

a Aged $\geq 5$ years; ${ }^{b}$ Cases per 1000 person-years at risk

of these two closely related tribes, and who had undergone the biennial research examinations.

Subjects developing ESRD were ascertained from the following sources: (1) A register of patients undergoing chronic renal dialysis, maintained by the Public Health Nursing Office in the Gila River Indian Community. (2) Patient registers for all dialysis centers in Phoenix and surrounding communities, as well as the Network 6 ESRD registry, which maintains information on all persons reported as initiating chronic dialysis in Arizona, New Mexico, and portions of southern Utah. These registers were searched for names of Indian subjects living in the Gila River Indian Community. All registers were reviewed by two of the authors to ensure that every subject living in the community who received dialysis was identified and that persons living outside the community were excluded. (3) Medical records of all members of the population who died during the study period. These records were compiled from review of available clinical data and encompassed all deaths since January 1, 1975, the starting point of this investigation. This review included clinical records of the Public Health Service Indian Hospital at Sacaton, Arizona, which provides primary care for this population and maintains records on all patient referrals outside the community; of the Phoenix Indian Medical Center, the principal referral hospital; and of any other hospital that provided care to a subject during the period immediately preceding death. In addition, death certificates, autopsy findings, and medical examiners' reports were reviewed. These data were used to identify subjects with ESRD who did not receive dialysis. The diagnosis of ESRD in these persons was based on clinical evidence of severe progressive azotaemia (including serum creatinine $\geq 442 \mu \mathrm{mol} / \mathrm{l})$. Because it was assumed that subjects with ESRD did not survive without receiving dialysis or renal transplants, no attempt was made to identify persons with renal failure who were still alive and not receiving renal replacement therapy.

The onset of ESRD was defined as the date of beginning chronic dialysis or, for azotaemic subjects not receiving dialysis, the date of death from chronic renal disease. All subjects who had renal transplants began dialysis prior to transplantation, and for them the start of dialysis was used as the date of onset of ESRD.

In each subject with ESRD, the clinical record from the Sacaton Hospital was reviewed to determine the cause of renal failure. Infor- mation regarding past disease history, the presence or absence of haematuria, proteinuria, hypertension, recurrent kidney infections, and urinary tract obstruction was abstracted from these records. This information was based on usual clinical practice rather than on testing as part of a standardised protocol and was therefore of variable completeness. ESRD was attributed to diabetic nephropathy if the subject had diabetes and chronic persistent proteinuria without other demonstrable causes of renal disease (e.g., evidence of renal disease prior to onset of diabetes, or renal impairment from drugs, obstruction, infection, or other acquired or congenital disease). Additionally, autopsy findings were available for seven subjects, and kidney biopsy findings were available for one subject. All seven autopsies were performed on diabetic subjects, and all had histologic findings consistent with diabetic nephropathy. The kidney biopsy, performed on a young nondiabetic woman, showed chronic membranoproliferative glomerulonephritis.

\section{Statistical analysis}

Incidence was expressed as the number of new cases of ESRD per 1000 person-years of observation for subjects within the community. The numerator was the number of new cases of ESRD between January 1, 1975 and June 30, 1986, and the denominator was the number of person-years at risk for ESRD. Person-time was accumulated only while subjects lived within the community. The period of risk began on either January 1, 1975 or the date of the subject's first biennial examination, whichever was later; it extended to the date of ESRD onset, death, emigration from the community, or close of the study (June 30, 1986), whichever was earlier. Subjects who developed diabetes during the study period accumulated person-time in the nondiabetic stratum before, and in the diabetic stratum after, the date of diagnosis of diabetes. Likewise, as subjects changed from one age, diabetes duration, or hypertension stratum to another during the course of the study, their person-time within each category accumulated during the corresponding time periods.

Cumulative incidence, which was estimated from the incidence rates observed during the study period, represents the percent of subjects who would have ESRD at the end of each specified period of diabetes duration if the duration-specific incidence rates were constant during these intervals and all subjects survived until the end of each period [8].

Incidence-rate ratios were used to assess the effect of dichotomous variables on the incidence of ESRD. These ratios and their confidence intervals were computed by a modification of the Mantel and Haenszel procedure [9] proposed by Rothman and Boice [10]. The effect of continuous variables was evaluated with a $\chi^{2}$ test by grouping the values of the variables and assessing average partial association in three-way contingency tables under the multiple hypergeometric model while controlling for the effects of a set of covariables [11]. This procedure was modified for person-time 
Table 3. Incidence of end-stage renal disease in diabetic Pima Indians, by attained age and sex

\begin{tabular}{|c|c|c|c|c|c|c|c|}
\hline \multirow[b]{2}{*}{$\begin{array}{l}\text { Attained } \\
\text { age (years) }\end{array}$} & \multicolumn{3}{|l|}{ Men } & \multicolumn{3}{|l|}{ Women } & \multirow{2}{*}{$\begin{array}{l}\text { Incidence } \\
\text { Ratio } \\
\text { (men/women) }\end{array}$} \\
\hline & $\begin{array}{l}\text { Person-years } \\
\text { at risk }\end{array}$ & Cases & Incidence $^{\mathrm{a}}$ & $\begin{array}{l}\text { Person-years } \\
\text { at risk }\end{array}$ & Cases & Incidence $^{\mathrm{a}}$ & \\
\hline $5-34$ & 609 & 0 & 0 & 845 & 0 & 0 & - \\
\hline $35-44$ & 834 & 4 & 4.8 & 906 & 3 & 3.3 & 1.5 \\
\hline $45-54$ & 720 & 12 & 16.7 & 1263 & 12 & 9.5 & 1.8 \\
\hline $55-64$ & 499 & 12 & 24.0 & 999 & 15 & 15.0 & 1.6 \\
\hline $65-74$ & 387 & 3 & 7.8 & 563 & 10 & 17.8 & 0.4 \\
\hline$\geq 75$ & 207 & 2 & 9.7 & 274 & 3 & 10.9 & 0.9 \\
\hline
\end{tabular}

a Cases per 1000 person-years at risk

Table 4. Incidence of end-stage renal disease in diabetic Pima Indians, by age at diagnosis of diabetes and sex

\begin{tabular}{|c|c|c|c|c|c|c|}
\hline \multirow{2}{*}{$\begin{array}{l}\text { Age at } \\
\text { diagnosis of } \\
\text { diabetes (years) }\end{array}$} & \multicolumn{3}{|l|}{ Men } & \multicolumn{3}{|l|}{ Women } \\
\hline & $\begin{array}{l}\text { Person-years } \\
\text { at risk }\end{array}$ & Cases & Incidence $^{\mathrm{a}}$ & $\begin{array}{l}\text { Person-years } \\
\text { at risk }\end{array}$ & Cases & Incidence $^{\mathrm{a}}$ \\
\hline$<25$ & 450 & 3 & 6.7 & 607 & 6 & 9.9 \\
\hline $25-34$ & 903 & 9 & 10.0 & 1176 & 7 & 6.0 \\
\hline $35-44$ & 924 & 13 & 14.1 & 1482 & 15 & 10.1 \\
\hline $45-54$ & 524 & 6 & 11.5 & 991 & 10 & 10.1 \\
\hline $55-64$ & 273 & 1 & 3.7 & 454 & 4 & 8.8 \\
\hline$\geq 65$ & 183 & 1 & 5.5 & 140 & 1 & 7.1 \\
\hline
\end{tabular}

a Cases per 1000 person-years at risk

denominators as recommended by Rothman and Boice [10]. These analyses were restricted to subjects at least 35 years of age, as no cases of ESRD occurred in subjects below this age.

\section{Results}

During the study period, 5059 subjects five years of age or older were at risk for developing ESRD. Of these, 750 had diabetes at the beginning of the study and an additional 387 were diagnosed during the study period. The mean age at diagnosis of diabetes for this population was 43 years (range 10 to 82 years). Clinical data on the age, diabetes status, and diabetes duration of all subjects at the beginning of followup are presented in Table 1. Eighty persons (36 men, 44 women) developed ESRD. Incidence rates of ESRD in the diabetic and nondiabetic subjects are presented in Table 2. The incidence rate of ESRD in diabetic subjects was 62 -fold ( $95 \%$ confidence interval, 20 to 188 , controlled for age and sex) the rate in those without diabetes. Of the 76 diabetic subjects with ESRD, 47 (21 men, 26 women) received dialysis and 29 (12 men, 17 women) died without receiving dialysis. Two of the diabetic men also received renal transplants. Among the diabetic subjects, ESRD was attributed to diabetic nephropathy in all but two, in whom chronic urinary tract obstruction led to ESRD.

Only four subjects with ESRD ( 3 men, 1 woman) did not have diabetes. Three had glomerulonephritis, and one with benign prostatic hypertrophy had recur-
Table 5. Incidence of end-stage renal disease in diabetic Pima Indians by duration of diabetes

\begin{tabular}{llcc}
\hline $\begin{array}{l}\text { Diabetes } \\
\text { duration (years) }\end{array}$ & $\begin{array}{l}\text { Person-years } \\
\text { at risk }\end{array}$ & Cases & Incidence $^{\text {a }}$ \\
\hline $0-4$ & 2162 & $2^{b}$ & 0.9 \\
$5-9$ & 2038 & 0 & 0 \\
$10-14$ & 1934 & 14 & 7.2 \\
$15-19$ & 1287 & 32 & 24.9 \\
$\geq 20$ & 686 & 28 & 40.8 \\
\hline
\end{tabular}

a Cases per 1000 person-years at risk; ${ }^{b}$ Neither case in this diabetes duration category was due to diabetic nephropathy; both were due to obstructive uropathy

rent urinary tract infections and obstructive uropathy. Three of these four subjects underwent dialysis, and two subsequently had renal transplants; one died without receiving either dialysis or renal transplant.

Age-sex-specific incidence rates of ESRD in diabetic subjects are presented in Table 3 . Incidence rates in men and women were not significantly different when controlled for age and duration of diabetes, with a male to female rate ratio of 1.4 (95\% confidence interval, 0.9 to 2.3). No cases of ESRD occurred in subjects less than 35 years of age. The incidence of ESRD rose with increasing age until ages 55-64 years in men and 65-74 years in women. Attained age, however, was not a significant risk factor for ESRD when controlled for sex and duration of diabetes $\left(\chi^{2}=7.8\right.$, $\mathrm{df}=4, p=0.1$ ). Likewise, age at diagnosis of diabetes was not a significant risk factor for development of 


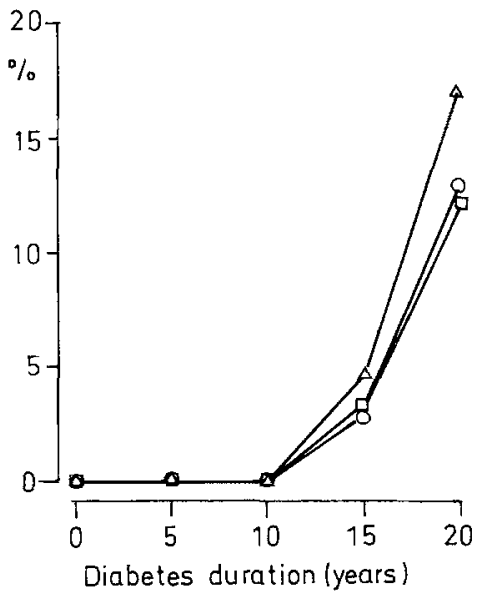

Fig. 1. Cumulative incidence (percent) of endstage renal disease attributed to diabetic nephropathy in diabetic Pima Indians, according to duration of diabetes and age at onset of diabetes. Age at diagnosis: $<35(\mathrm{O}) ; 35-54(\triangle) ; \geq 55$ (匚) years

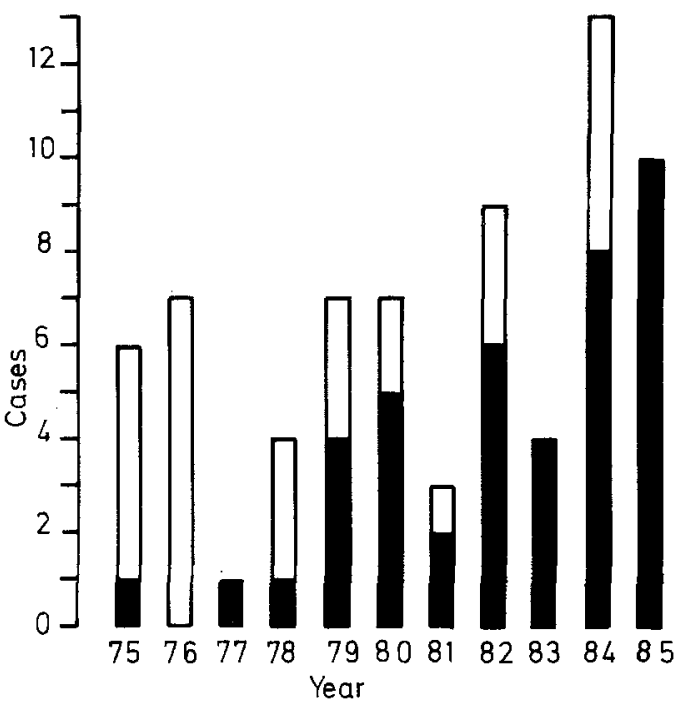

Fig. 2. New cases of end-stage renal disease in diabetic Pima Indians. Cases were ascertained at the initiation of dialysis treatment or at death in subjects not receiving dialysis but with evidence of end-stage renal disease. Deaths $(\square)$; dialysis (

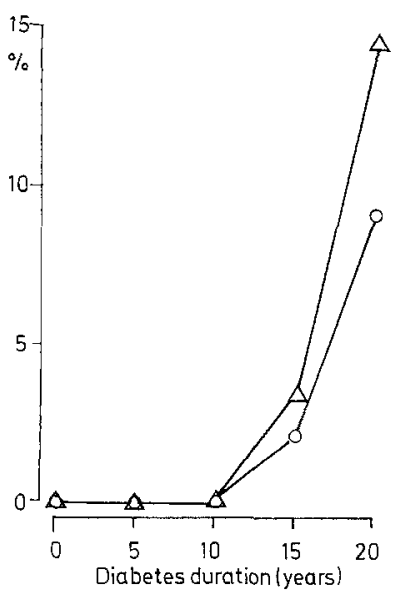

Fig. 3. Comparison of cumulative incidence (percent) of endstage renal disease attributed to diabetic nephropathy in Pima Indians with Type 2 (noninsulin-dependent) diabetes $(\triangle)$ and in subjects with Type 1 (insulin-dependent) diabetes $(O)$ followed at the Joslin Clinic, Boston, Massachusetts, USA [12]

$\operatorname{ESRD}\left(\chi^{2}=4.0, \mathrm{df}=3, p=0.3\right)$ when controlled for sex and diabetes duration. The incidence of ESRD in diabetic subjects according to age at diagnosis of diabetes and sex is presented in Table 4.
Diabetes duration was significantly associated with the incidence rate of ESRD $\left(\chi^{2}=89.9, \mathrm{df}=4\right.$, $p<0.001$, controlled for age and sex). The incidence of ESRD by duration of diabetes is presented in Table 5 . No cases of ESRD due to diabetic nephropathy occurred in subjects with diabetes of less than 10 years duration. The cumulative incidence of ESRD attributed to diabetic nephropathy as a function of diabetes duration, by age at onset of diabetes, is shown in Figure 1.

The presence of hypertension (systolic blood pressure $\geq 160 \mathrm{~mm} \mathrm{Hg}$ or diastolic blood pressure $\geq 95 \mathrm{~mm} \mathrm{Hg}$ ) was significantly associated with a higher incidence of ESRD. The rate of ESRD in subjects with hypertension was 3.8-fold (95\% confidence interval, 2.5 to 5.8 ) that in normotensive subjects when controlled for age, sex, and duration of diabetes.

The numbers of new cases of ESRD among diabetic Pima Indians for each year of the study through 1985 are shown in Figure 2. Five additional dialysis-treated cases were identified in the first six months of 1986. The proportion of subjects with ESRD who did not receive dialysis was higher in the first half of the study. The incidence rate of dialysistreated renal disease increased significantly during the study period $\left(\chi^{2}=6.7, \mathrm{df}=2, p=0.04\right.$, controlled for age, sex, and duration of diabetes). When persons with ESRD who died without receiving dialysis were included, however, no significant change in the incidence rate over the study period was noted $\left(\chi^{2}=1.1\right.$, $\mathrm{df}=2, p=0.6$, controlled for age, sex, and duration of diabetes).

The incidence rate of ESRD attributed to diabetic nephropathy in Pima Indians with Type 2 diabetes of up to 20 years duration was compared with a previously reported rate for subjects from the Joslin Clinic (Boston, Massachusetts, USA) with Type 1 diabetes of similar duration [12]. When controlled for the duration of diabetes, the incidence of ESRD in subjects with Type 2 and in those with Type 1 diabetes was similar [incidence rate ratio $=1.6(95 \%$ confidence interval, 0.9 to 2.8)]. Duration-specific cumulative incidence rates of ESRD among Type 1 and Type 2 diabetic subjects are shown in Figure 3.

\section{Discussion}

The vast majority (95\%) of ESRD in Pima Indians occurred in diabetic subjects, and among these $97 \%$ appeared to be attributable to diabetic nephropathy. Although the diagnosis was based largely on clinical evidence in this study, previous detailed postmortem histologic examination of the kidneys in 43 diabetic and 62 nondiabetic Pima Indians showed that intercapillary glomerulosclerosis was the predominant form of renal disease among diabetic Pima Indians [4]. Thus, 
renal disease and ESRD in diabetic Pima Indians are primarily due to diabetic nephropathy. Incidence rates of ESRD not due to diabetic nephropathy were similar for diabetic and nondiabetic Pima Indians in the present study.

The proportion of cases of ESRD attributed to diabetic nephropathy in Pima Indians is far greater than the 25\% estimated for the general United States population [1]. This disparity is probably due to the much higher prevalence of diabetes in the Pima population. The age-sex-adjusted prevalence of Type 2 diabetes in the Pima Indians is 13-fold that of the primarily Caucasian population of Rochester, Minnesota, USA [3]. Greater frequencies of dialysis-treated ESRD and higher proportions of ESRD attributed to diabetic nephropathy are also found in other minority groups, including Blacks and Hispanics [1, 13, 14], who have greater prevalences of diabetes than the general United States population [15-18]. By contrast, although the Zuni Indians of New Mexico have higher rates of ESRD than the general United States population [19], they have a much higher proportion of chronic glomerulonephritis (40\% of ESRD) and a much lower proportion of diabetic nephropathy ( $24 \%$ of ESRD) than the Pima Indians [20].

Use of dialysis for diabetes-related ESRD has increased during the past decade. This increase has occurred not only in the Pima Indians, but also in the United States in general and in the United Kingdom $[1,21]$. Much of the reported increase in the number of diabetic subjects who have dialysis-treated renal disease is probably due to the changing criteria for initiation of dialysis rather than to an increasing incidence of end-stage disease. Diabetic Pima Indians show no significant change in the incidence rate of all ESRD during the study period, despite an increase in the incidence of dialysis-treated renal disease.

Hypertension (systolic blood pressure $\geq 160 \mathrm{mmHg}$ or diastolic blood pressure $\geq 95 \mathrm{~mm} \mathrm{Hg}$ ) was a risk factor for ESRD in the present study. Hypertension has been shown to be a risk factor for nephropathy in Type 1 diabetes [22-26] but a recent longitudinal study from the Mayo clinic [27] did not find an association between hypertension at the time of diagnosis of diabetes and the subsequent development of proteinuria in subjects with Type 2 diabetes. An assessment of the relationship between hypertension and diabetic renal disease, however, is difficult as hypertension can cause proteinuria and renal insufficiency and can also be a consequence of progressive diabetic renal disease. Thus the present findings do not indicate whether hypertension contributed to or resulted from the diabetic nephropathy. In a recent study of Pima Indians, however, blood pressure before the onset of diabetes predicted abnormal albumin excretion after the onset of diabetes, suggesting that the higher blood pressure seen in diabetic nephropathy is not entirely the result of the renal disease but may precede and contribute to it [28].
In diabetic Pima Indians, neither age at diagnosis of diabetes nor attained age had significant effects on the incidence of ESRD when controlled for duration of diabetes. Likewise, no significant difference in ESRD rates was observed between men and women. Diabetes duration, however, was a highly significant predictor of ESRD. The cumulative incidence of this complication was $15 \%$ at 20 years duration of diabetes (Fig. 3).

Published estimates of the incidence rates of ESRD in the United States Medicare population and among diabetic persons in Nebraska, USA [1, 2, 29] are based on data for subjects beginning dialysis. These studies underestimate the actual rate of ESRD because they do not include persons dying with renal disease without receiving dialysis. Additionally, studies that determine incidence rates of ESRD in the United States population, based on Medicare data [1, 29], underestimate the actual incidence rate because about $7 \%$ of persons with dialysis-treated renal disease are not covered by Medicare [1]. For comparisons with these reports, rates in Pima Indians with dialysis-treated renal disease were used.

The incidence rate of dialysis-treated renal disease due to all causes in Pima Indians (1860 cases/million person-years; $95 \%$ confidence interval, 1320 to 2390 , age-sex-adjusted to the 1980 United States Census population) was 23 -fold as high as the rate of 82 new cases per million person-years reported by Eggers et al. [1] in the 1980 United States population covered by Medicare. This comparison does not account for differences between the two populations in prevalence or duration of diabetes.

The annual incidence rate of ESRD among known diabetic persons in the United States population has been estimated by using Medicare data in persons for whom the cause of ESRD was reported (about half the cases) and extrapolating to data on the prevalence of diagnosed diabetes in the United States population [29]. Differentiation between persons with Type 1 and Type 2 diabetes was not possible, and the duration of diabetes was unknown. Incidence rates of ESRD in the diabetic Pima Indians, however, were 14-fold as high as the estimates for the United States diabetic population aged 45-64 years and 10-fold as high as in those aged 65 years and older. The higher incidence of ESRD for diabetic Pima Indians in these two age groups may be due to a greater proportion of subjects with long-duration diabetes as a result of an earlier age of onset. By contrast, in the 15-44 year-old age group, the rate of ESRD in diabetic Pima Indians was only 1.2-fold the rate in the United States diabetic population, in whom a greater proportion of long-duration diabetes may exist, primarily as the result of the usually early age of onset of Type 1 diabetes. Type 1 diabetes does not occur in the Pima Indians [30]. Absence of data on the incidence of ESRD in the United States by duration of diabetes and the fact that only 
about half of the ESRD cases in the United States population have a stated cause limit interpretation of these apparent differences.

To our knowledge, only one study has compared the incidence rate of ESRD by type of diabetes [2]. In that study of Nebraska residents, the incidence of ESRD (per 100,000 person-years) was 411 for persons with Type 1 diabetes, and 26 for persons with Type 2 diabetes, age-adjusted to the 1980 known-diabetic population of the state. Although these findings suggest that the incidence rate of ESRD in Nebraska is substantially less in persons with Type 2 diabetes, incidence could not be analysed as a function of duration of diabetes. The persons with Type 2 diabetes and ESRD had a mean age of 62 years, and on average they were 23 years older and had diabetes for six years less than those with Type 1 diabetes. As a consequence, persons with Type 2 diabetes had greater competing risks of death and were less likely to survive long enough to have diabetes of sufficient duration for nephropathy to develop. If the Nebraska study could be controlled for duration of diabetes, the disparity between the rate of ESRD for subjects with Type 1 and those with Type 2 diabetes would be expected to diminish and might even disappear.

Supporting this postulate is the fact that, in the present study, after controlling for duration of diabetes, the cumulative incidence of ESRD attributed to diabetic nephropathy in Pima Indians with diabetes of up to 20 years duration was at least as great as that of the Joslin Clinic population (Fig.3). This finding emphasizes the need for including diabetes duration in comparisons of the risk of ESRD between persons with Type 1 and Type 2 diabetes. Although genetic and environmental differences exist between Pima Indians and persons at the Joslin Clinic or those in Nebraska, the contribution of duration of diabetes to the development of diabetic renal disease is clearly of great importance.

In conclusion, the duration of diabetes was a significant risk factor for ESRD in diabetic Pima Indians. Additionally, hypertension was predictive of ESRD in this population. The rate of ESRD was similar in men and women, was not affected by age at diagnosis of diabetes or by attained age, and did not change significantly between 1975 and 1986. The finding that the incidence rate (controlled for duration) of ESRD attributed to diabetic nephropathy in Type 2 diabetic Pima Indians was similar to that in persons with Type 1 diabetes has important implications. These observations suggest that renal failure may result from long-duration Type 2 diabetes as frequently as from Type 1 diabetes. Improved survival of persons with Type 2 diabetes, an increasing incidence of this disease, and a relatively early age of onset in many populations could lead to a dramatic increase in the incidence of end-stage renal disease in the future.
Acknowledgement. The authors are indebted to the members of the Gila River Indian Community for participating in this investigation; to the staff of the Diabetes and Arthritis Epidemiology Section, NIDDK, for conducting examinations and processing data; to the staff of the Public Health Service Indian Hospital, Sacaton, for providing access to the clinical records; to Ms. D. Garcia-Smith and the Public Health Nursing staff of the Gila River and Salt River Indian Communities for assisting in identifying subjects with end-stage renal disease; to the staff of the Network 6 end-stage renal disease registry for facilitating access to their registry; to Dr. D.A. Reichert and the staffs of the local dialysis centers for providing assistance; and to Dr. A.S. Krolewski of the Joslin Clinic for supplying data on incidence of end-stage renal disease in insulin-dependent diabetic subjects.

\section{References}

1. Eggers PW, Connerton R, McMullan M (1984) The Medicare experience with end-stage renal disease: trends in incidence, prevalence, and survival. Health Care Financing Review 5: 69-88

2. Rettig B, Teutsch SM (1984) The incidence of end-stage renal disease in type I and type II diabetes mellitus. Diabetic Nephropathy $3: 26-27$

3. Knowler WC, Bennett PH, Hamman RF, Miller M (1978) Diabetes incidence and prevalence in Pima Indians: a 19-fold greater incidence than in Rochester, Minnesota. Am J Epidemiol 108: 497-505

4. Kamenetzky SA, Bennett PH, Dippe SE, Miller M, LeCompte PM (1974) A clinical and histologic study of diabetic nephropathy in the Pima Indians. Diabetes 23: 61-68

5. Pettitt DJ, Knowler WC, Lisse JR, Bennett PH (1980) Development of retinopathy and proteinuria in relation to plasmaglucose concentrations in Pima Indians. Lancet II: 1050-1052

6. Bennett PH, Burch TA, Miller M (1971) Diabetes mellitus in American (Pima) Indians. Lancet II: 825-828

7. World Health Organization (1985) Diabetes mellitus. Monograph Series No 727 , Geneva

8. Kleinbaum DG, Kupper LL, Morgenstern H (1982) Epidemiologic research: principles and quantitative methods. Van Nostrand Reinhold, New York, pp96-116

9. Mantel N, Haenszel W (1959) Statistical aspects of the analysis of data from retrospective studies of disease. $\mathbf{J}$ Natl Cancer Inst 22: 719-748

10. Rothman KJ, Boice JD (1979) Epidemiologic analysis with a programmable Calculator. National Institutes of Health (NIH publication no. 79-1649), Washington, pp 11-17

11. Landis JR, Heyman ER, Koch GG (1978) Average partial association in three-way contingency tables: a review and discussion of alternative tests. Int Stat Rev 46: 237-254

12. Krolewski AS, Warram JH, Christlieb AR, Busick EJ, Kahn CR (1985) The changing natural history of nephropathy in Type I diabetes. Am J Med 78: 785-794

13. Rostand SG, Kirk KA, Rutsky EA, Pate BA (1982) Racial differences in the incidence of treatment for end-stage renal disease. N Engl J Med 306: 1276-1279

14. Pugh JA, Stern MP, Haffner SM, Eifler CW, Zapata M (1988) Excess incidence of treatment of end-stage renal disease in Mexican Americans. Am J Epidemiol 127: 135-144

15. Harris MI, Hadden WC, Knowler WC, Bennett PH (1987) Prevalence of diabetes and impaired glucose tolerance and plasma glucose levels in U.S. population aged $20-74$ yr. Diabetes 36 : 523-534

16. Roseman JM (1985) Diabetes in Black Americans. In: Harris MI, Hamman RF (eds) Diabetes in America. National Institutes of Health (NIH publication no.85-1468), Washington, VIII, pp 1-24

17. Gardner LI, Stern MP, Haffner SM, Gaskill SP, Hazuda HP, Re- 
lethford JH, Eifler CW (1984) Prevalence of diabetes in Mexican Americans: relationship to percent of gene pool derived from native American sources. Diabetes 33: 86-92

18. Stern MP (1985) Diabetes in Hispanic Americans. In: Harris MI, Hamman RF (eds) Diabetes in America. National Institutes of Health (NIH publication no.85-1468), Washington, IX, pp 1-11

19. Hoy WE, Megill DM, Hughson MD (1987) Epidemic renal disease of unknown etiology in the Zuni Indians. Am $\mathbf{J}$ Kidney Dis 9: $485-496$

20. Pasinski R, Pasinski M (1987) End-stage renal disease among the Zuni Indians: 1973-1983. Arch Intern Med 147: 1093-1096

21. Cameron JS, Challah S (1986) Treatment of end-stage renal failure due to diabetes in the United Kingdom, 1975-84. Lancet II: $962-966$

22. Parving HH, Andersen AR, Smidt UM, Oxenbøll B, Edsberg B, Sandahl Christiansen J (1983) Diabetic nephropathy and arterial hypertension. Diabetologia 24: 10-12

23. Mogensen CE, Christensen CK (1984) Predicting diabetic nephropathy in insulin-dependent patients. $\mathrm{N}$ Engl J Med 311: 89-93

24. Christlieb AR, Warram JH, Krolewski AS, Busick EJ, Ganda OP, Asmal AC, Soeldner JS, Bradley RF (1981) Hypertension: the major risk factor in juvenile-onset insulin-dependent diabetics. Diabetes 30 [Suppl. 2]: 90-96

25. Krolewski AS, Canessa M, Warram JH, Laffel LMB, Christlieb AR, Knowler WC, Rand LI (1988) Predisposition to hypertension and susceptibility to renal disease in insulin-dependent diabetes mellitus. N Engl J Med 318: 140-145
26. Mangili R, Bending JJ, Scott G, Lai KL, Gupta A, Viberti GC (1988) Increased sodium-lithium countertransport activity in red cells of patients with insulin-dependent diabetes and nephropathy. N Engl J Med 318: 146-150

27. Ballard DJ, Humphrey LL, Melton LJ, Frohnert PP, Chu C-P, O'Fallon WM, Palumbo PJ (1988) Epidemiology of persistent proteinuria in type II diabetes mellitus: population-based study in Rochester, Minnesota. Diabetes 37: 405-412

28. Knowler WC, Bennett PH, Nelson RG (1988) Prediabetic blood pressure predicts albuminuria after development of NIDDM. Diabetes 37 [Suppl.]: 120 (Abstract)

29. Herman WH, Teutsch SM (1985) Kidney diseases associated with diabetes. In: Harris MI, Hamman RF (eds) Diabetes in America. National Institutes of Health (NIH publication no. 85-1468), Washington, XIV, pp1-31

30. Knowler WC, Bennett PH, Bottazzo GF, Doniach D (1979) Islet cell antibodies and diabetes mellitus in Pima Indians. Diabetologia 17: 161-164

Received: 25 March 1988

and in revised form: 8 August 1988

Dr. Nelson

National Institute of Diabetes

and Digestive and Kidney Diseases

1550 E. Indian School Road

Phoenix, Arizona 85014

USA 